OPEN ACCESS

Edited by:

Peter Sykora,

Georgetown University, United States

Reviewed by:

Georges Janssens,

Academic Medical Center,

Netherlands

Konstantinos Palikaras,

National and Kapodistrian University of

Athens, Greece

*Correspondence:

Collin Y. Ewald

collin-ewald@ethz.ch

Specialty section: This article was submitted to Interventions in Aging, a section of the journal

Frontiers in Aging

Received: 15 July 2021

Accepted: 26 August 2021

Published: 08 September 2021

Citation:

Ewald CY (2021) Drug Screening Implicates Chondroitin Sulfate as a

Potential Longevity Pill.

Front. Aging 2:741843.

doi: 10.3389/fragi.2021.741843

\section{Drug Screening Implicates Chondroitin Sulfate as a Potential Longevity Pill}

\author{
Collin Y. Ewald*
}

Laboratory of Extracellular Matrix Regeneration, Department of Health Sciences and Technology, Institute of Translational Medicine, ETH Zürich, Switzerland

Discovering compounds that promote health during aging ("geroprotectors") is key to the retardation of age-related pathologies and the prevention of chronic age-related diseases. In in-silico and model organisms' lifespan screens, chondroitin sulfate has emerged as a geroprotective compound. Chondroitin sulfate is a glycosaminoglycan attached to extracellular matrix proteins and is naturally produced by our body. Oral supplementation of chondroitin sulfate shows a high tolerance in humans, preferable pharmacokinetics, a positive correlation with healthy human longevity, and efficacy in deceleration of age-related diseases in randomized clinical trials. We have recently shown that chondroitin sulfate supplementation increases the lifespan of $C$. elegans. Thus, chondroitin sulfate holds the potential to become a geroprotective strategy to promote health during human aging. This review discusses the two major potential mechanisms of action, extracellular matrix homeostasis and inhibition of inflammation, that counteract age-related pathologies upon chondroitin sulfate supplementation.

\begin{abstract}
Keywords: chondroitin sulfate, supplement, healthy aging, longevity, anti inflammatory, extracellar matrix, drug discovery, matreotype
\end{abstract}

\section{INTRODUCTION}

\section{Predicted Longevity Drug-Protein Targets Reveal Chondroitin}

How to identify compounds that retard age-related pathologies and promote health during aging? There are many approaches to identify geroprotective compounds, spanning from in-silico and cellbased drug screening to direct lifespan assays in model organisms (Barardo et al., 2017; Bakula et al., 2018; Janssens et al., 2019; Kusumoto et al., 2021; Statzer et al., 2021). One of the largest screens assessed 1,300 compounds on about 20,000 mice performing full lifespans and yielded five longevitypromoting compounds (WO2018075641A1 and US $20200254006 \mathrm{A1}$ ). Using C. elegans, more than 100,000 compounds have been screened collectively across multiple studies, and about 100 compounds have been identified that increase C. elegans lifespan (Petrascheck et al., 2007; Lucanic et al., 2013; Ye et al., 2014; Kim and Lee, 2019; Statzer et al., 2021). Pathway analysis of these discovered longevity compounds showed enrichment for TGF $\beta$ pathway, chondroitin, and heparan sulfate biogenesis as potential drug-protein targets (Liu et al., 2016). In our drug screens, we also identified chondroitin sulfate (Statzer et al., 2021). Chondroitin sulfate is a naturally occurring sulfated glycosaminoglycan usually attached to extracellular matrix proteins (Figure 1). Thereby, it is abundantly found in connective tissues, such as cartilage that cushions the ends of the bones within the joints, skin, blood vessels, ligaments, and tendons, but also in other organs, such as the brain (Jerosch, 2011; Kwok et al., 2012). Chondroitin sulfate is a popular and widely used supplement that 


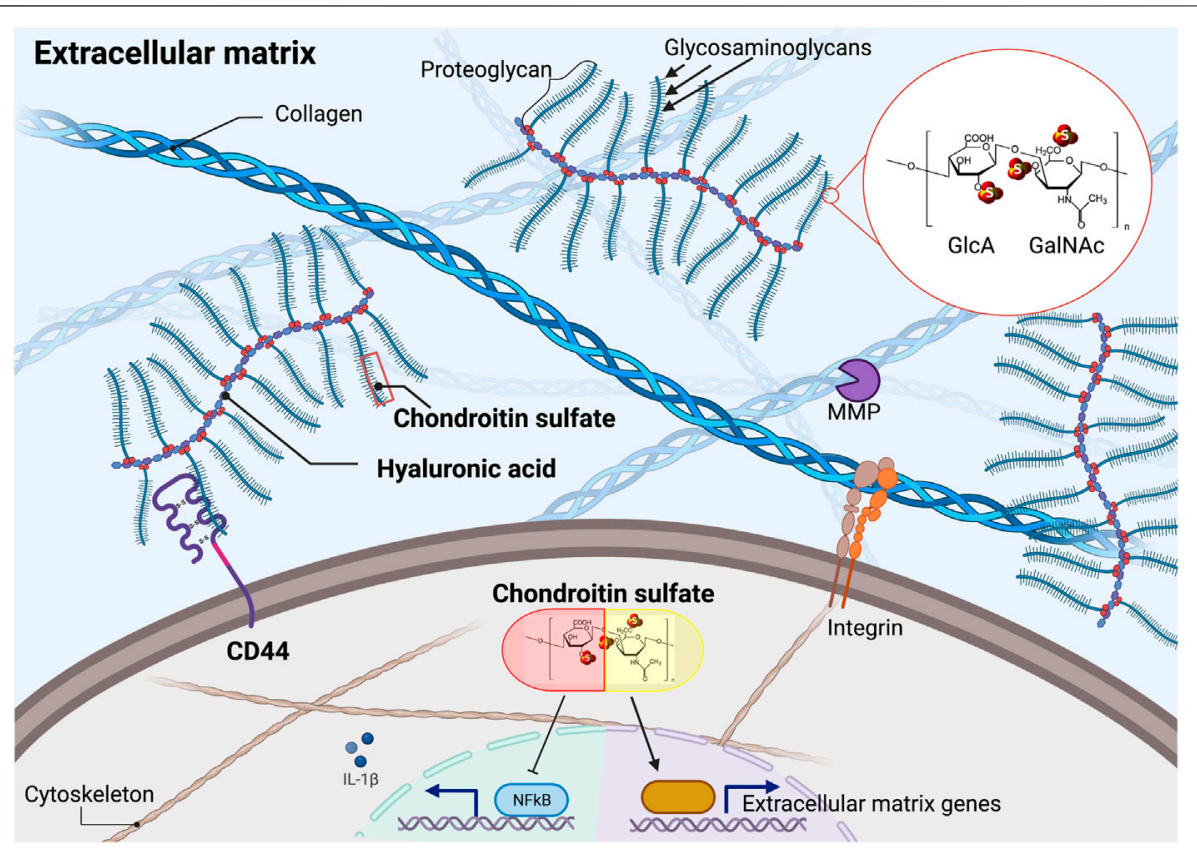

FIGURE 1 | Chondroitin sulfate in the extracellular matrix and cellular effects of supplementation. Chondroitin sulfate consists of repeating units of D-glucuronic acid (GlcA) and N-acetyl galactosamine (GalNAc). Naturally occurring chondroitin sulfate only shows one of the three sulfates at the indicated (S) positions, resulting in distinct isomers. Chondroitin sulfate polymers are the building blocks of proteoglycans that can be attached to the hyaluronic acid polymers. Supplementation of chondroitin sulfate blocks NF-kB mediated inflammation and stimulates extracellular matrix homeostasis. MMP = matrix metalloproteinase. Illustration not drawn to scale.

is well-tolerated, with no adverse effects above placebo, and is likely very safe, allowing long-term treatment (Hathcock and Shao, 2007). Thus, making chondroitin sulfate an ideal candidate to develop further into a geroprotective compound.

\section{In-vivo Drug Screen C. Elegans Identifies Glycosaminoglycans to Extend Lifespan}

While examining previously established longevity compounds, such as metformin and rapamycin, we noticed a robust extracellular matrix transcriptional signature as a cellular response to the drug (Statzer et al., 2021). Moreover, in 41 out of 47 known longevity compounds (i.e., almost 90\%) we examined, extracellular matrix gene expression was significantly altered (Statzer et al., 2021), suggesting remodeling of the extracellular matrix elicited by these drugs (Ewald, 2020). Therefore, in contrast to previous drug screens, we centered our in-silico analysis around the extracellular matrix (Ewald, 2020). We analyzed the human Genotype-Tissue Expression (GTEx) transcriptomic data combined with eight different expression profile datasets to define the aging matreotype across tissues (Statzer et al., 2021). The aging matreotype is a list of 99 extracellular matrix genes that either decline or increase in expression during human aging (Statzer et al., 2021). Then we probed the cMap expression profiles of about 1,300 drugs for a "youthful" matreotype signature and identified 185 compounds, of which 24 have previously been shown to increase lifespan in model organisms (Statzer et al., 2021).

A challenge in validating compounds for healthy aging is to identify the beneficial drug dose. We developed a novel in-vivo surrogate marker for longevity, using collagen homeostasis as a read- out in C. elegans (Statzer et al., 2021). With this reporter, we examined the unexplored area of proteoglycans and glycosaminoglycans as they were identified as major drug targets across many geroprotective drugs (Liu et al., 2016). These glycosaminoglycans, such as hyaluronic acid, chondroitin sulfate, and glucosamine, are major components of extracellular matrix proteins, found in cartilage and synovial fluid, and are naturally produced by the body or can be supplemented by diet (Jerosch, 2011). We found that supplementing hyaluronic acid and chondroitin sulfate increased C. elegans lifespan by $25-35 \%$ and 23-28\%, respectively (Statzer et al., 2021). Previous work by the Ristow lab had shown that supplementation with glucosamine increased mouse lifespan and also C. elegans lifespan by $8-12 \%$ (Weimer et al., 2014). Thus, oral uptake of these glycosaminoglycans promotes healthy aging and longevity in model organisms.

\section{Biosynthesis of Chondroitin and Relationship to Glucosamine and Hyaluronic Acid}

Glucosamine is a precursor and the rate-limiting step in the synthesis of chondroitin polymers, which are the building blocks of the side chains of several proteoglycans (Figure 1) (McCarty et al., 2000; Mikami and Kitagawa, 2013). In particular, chondroitin consists of long polysaccharides of 20-200 repeating units of $\mathrm{N}$-acetyl galactosamine (GalNAc) and D-glucuronic acid (GlcA), which can be sulfated at three different positions resulting in distinct isomers (Figure 1) (Mikami and Kitagawa, 2013). Chondroitin sulfate is usually of $10-50 \mathrm{kDa}$ molecular weight and is extracted from 
cartilaginous tissues from pigs, cows, birds, and sharks (Jerosch, 2011). Glucosamine and chondroitin sulfate may facilitate hyaluronic acid production (McCarty et al., 2000).

Following oral uptake, glucosamine, chondroitin sulfate, and hyaluronic acid get transported to the target tissue in animal studies; molecules are safe and show high-quality evidence for their effectiveness in randomized clinical trials (Balogh et al., 2008; Bruyère et al., 2008; Jerosch, 2011; Garantziotis and Savani, 2019). However, hyaluronic acid is a huge polymer that is poorly uptaken by the body and showed variable effects in randomized clinical trials (Kalman et al., 2008). Furthermore, hyaluronic acid needs to be broken down by hyaluronidase TMEM2 to protect against protein misfolded endoplasmic reticulum stress in human fibroblasts and promote C. elegans longevity (Schinzel et al., 2019). Glucosamine is a smaller monomer but impairs glucose metabolism and increases lifespan in part through glucose restriction and mitochondrial reactive oxygen species-induced hormesis (Weimer et al., 2014). On the other hand, chondroitin sulfate is a slow-acting drug (Bruyère et al., 2008) that has supportive evidence to modify cartilage structure in randomized clinical trials and is repeatedly recommended for the last 20 years by the European League Against Rheumatism (EULAR) (Jordan et al., 2003; Kloppenburg et al., 2018). Furthermore, the combination of glucosamine with chondroitin sulfate showed synergistic and additive effects for osteoarthritis in vitro, in vivo, and in randomized clinical trials (Clegg et al., 2006; Jerosch, 2011), suggesting distinct and overlapping modes-of-action. Hence, I focus here on the potential underlying mode-of-actions and molecular mechanisms promoted by supplementation with chondroitin sulfate.

\section{POTENTIAL MECHANISMS PROMOTED BY CHONDROITIN SULFATE}

\section{Mechanism 1: Evidence of Chondroitin Sulfate Stimulating Extracellular Matrix Protein Homeostasis}

During aging, the balance of extracellular matrix biosynthesis and degradation becomes dysregulated (Ewald, 2020). Genetic alterations of extracellular matrix genes cause diverse phenotypes and diseases (Huxley-Jones et al., 2008; Statzer and Ewald, 2020). While many chronic age-dependent diseases show increased inflammation and fibrotic collagen deposition (Wick et al., 2013; Bonnans et al., 2014; Teuscher et al., 2019; Haefke and Ewald, 2020; Karsdal et al., 2020), a general signature of extracellular matrix aging is the progressive decline in collagen biosynthesis and an increase of extracellular protease activity across species (Ewald, 2020). For instance, in human skin, collagen, elastic fibers, laminin, and integrin levels progressively decline during aging (Shuster et al., 1975; Bosset et al., 2003; Farage et al., 2008; Sugawara et al., 2008; Giangreco et al., 2009; Kanaki et al., 2016). The general decline of collagen biosynthesis might be driven by the senescence of fibroblasts and the loss of stem cell maintenance (Varani et al., 2006). Counteracting this age-dependent decline of collagen synthesis by prolonging collagen expression is sufficient to increase the lifespan of C. elegans (Ewald et al., 2015), suggesting that extracellular protein homeostasis is a novel yet unexplored mechanism to promote health during aging (Ewald, 2020).

Since domains of extracellular matrix proteins and remodeling enzymes are well conserved across species, particularly the active domains where drug target sites are preferentially located, the dynamic process of extracellular matrix remodeling has emerged as an attractive drug target (Huxley-Jones et al., 2008). In-silico analysis predicting chondroitin sulfate drug targets revealed mostly components for biosynthesis and degradation of chondroitins, such as chondroitinase (GALNS), sulfotransferase (CHST11), chondroitin/hyaluronic acid receptor (CD44), hyaluronidase (HYAL1, 2), and enzymes that remodel the extracellular matrix, such as matrix metalloproteinases (MMP1, 3, 16, 24) (Lila et al., 2018). In mice, deletion of chondroitin 6sulfotransferase (CHST3) results in an abnormal extracellular matrix in the brain, accelerated brain aging, and memory impairments (Yang et al., 2021). Overexpression of CHST3 improved memory in old mice, suggesting the importance of maintaining proper chondroitin sulfate levels to promote neuroplasticity during aging (Yang et al., 2021). Furthermore, endogenous chondroitin sulfate is essential for maintaining embryonic stem cell pluripotency via binding to E-cadherin cell adhesion and RhoA and ERK1/2 downstream signaling (Izumikawa et al., 2014). Hence, endogenous chondroitin sulfate metabolism is linked to extracellular protein homeostasis.

In rats, endogenous chondroitin sulfate levels decline with age, probably due to the loss of chondrocytes (Honda et al., 1979). Interestingly, supplementing chondroitin sulfate increased chondrocyte cell proliferation in a dose-dependent manner (Jerosch, 2011; López-Senra et al., 2020). Moreover, supplementing $C$. elegans with chondroitin sulfate retarded the progressive decline of collagen renewal and increased lifespan (Statzer et al., 2021). In proteomics analysis of osteoarthritis patient-derived chondrocytes, ex-vivo chondroitin sulfate supplementation mainly resulted in remodeling of extracellular proteins and some inflammatory-associated proteins (Calamia et al., 2012a). This is consistent with many animal and human studies showing that chondroitin sulfate supplementation inhibits cartilage destruction and stimulates proteoglycan production for bolstering the connective tissues (Bassleer et al., 1998; Omata et al., 2000; Tahiri et al., 2007; Huskisson, 2008; Taniguchi et al., 2011; Martel-Pelletier et al., 2015; Sukhikh et al., 2020). Taken together, supplementing with chondroitin sulfate tips the balance towards prolonged extracellular matrix protein homeostasis, a requisite for healthy aging (Figure 1).

\section{Mechanism 2: Evidence of Chondroitin Sulfate in Suppressing Inflammation}

Endogenous chondroitin sulfate is essential to keep inflammation in check. A spontaneously-arisen deleterious mutation in the chondroitin sulfate synthase 1 (Chsyl) resulted in lower chondroitin sulfate levels leading to chronic inflammation and shortening of mouse lifespan (Macke et al., 2020). On the other hand, chondroitin sulfate supplementation reduces chronic 
inflammation. For instance, in a randomized, double-blind, placebo-controlled, clinical trial on 18 placebo and 18 glucosamine and chondroitin supplemented healthy adults, chondroitin with glucosamine significantly lowered serum inflammation biomarker C-reactive Protein and substantially remodeled the extracellular matrix detected by the blood plasma proteomic arrays (Navarro et al., 2015). Similarly, chondroitin sulfate intake was associated with a reduction in C-reactive Protein concentration in the blood (Kantor et al., 2020), suggesting a decrease in inflammation.

Induction of an inflammatory response by stimulating chondrocytes with interleukin IL-1 $\beta$ or lipopolysaccharides (LPS) increases protein levels of inflammatory-associated proteins, such as complement components, and also matrix metalloproteinases that degrade extracellular matrices. This increase is attenuated by chondroitin supplementation (Chan et al., 2005; Monfort et al., 2005; Tahiri et al., 2007; Legendre et al., 2008; Campo et al., 2009; Calamia et al., 2010; Imada et al., 2010; Calamia et al., 2012b), supporting a molecular role of chondroitin sulfate in blocking inflammation and extracellular matrix degradation (Figure 1). Similarly, in mice arthritis models, chondroitin sulfate slowed cartilage destruction and partially blocked inflammation (Omata et al., 2000). Mechanistically, chondroitin sulfate inhibits translocation of NF-kB, thereby decreasing NF-kB downstream signaling resulting in lower levels of pro-inflammatory cytokines and enzymes, such as IL- $1 \beta$, IL-6, TNF- $\alpha$, Cox- 2 , and Nos-2 (Jomphe et al., 2007; Campo et al., 2008; Xu et al., 2008; Souich et al., 2009; Vallières and Souich, 2010) (Figure 1).

Interestingly, across species, including humans, NF-kB increases in several tissues during aging (Tilstra et al., 2011). Genetic inhibitions of NF-kB delay several age-related pathologies in mice (Tilstra et al., 2011). Furthermore, in the hypothalamus of old mice, NF-kB activation decreases lifespan, whereas NF-kB inhibition increases lifespan (Zhang et al., 2013). Pharmacological inhibition of NF-kB also increases the lifespan of Drosophila (Moskalev and Shaposhnikov, 2011). This suggests that some beneficial effects of chondroitin sulfate supplementation might be mediated through inhibiting NF-kB age-related chronic inflammation resulting in improved health and longevity.

Taken together, supplementation of chondroitin sulfate increases lifespan via improving extracellular matrix homeostasis and via inhibiting chronic inflammation. Chronic inflammation can lead to upregulation of matrix metalloproteinase and extracellular matrix fragmentation and degradation as seen in osteoarthritis, suggesting a mechanistic link between disease progression and aging. However, chondroitin sulfate supplementation can increase the lifespan of model organisms via both mechanisms independently: i.e., extracellular matrix remodeling or inhibiting chronic inflammation, suggesting distinct but also overlapping modes of action.

\section{EVIDENCE OF CHONDROITIN SULFATE PROMOTING HEALTHY AGING IN HUMANS}

\section{Uptake of Chondroitin Sulfate}

Is orally supplemented chondroitin sulfate being absorbed by the body, and does it reach the target tissue? In rats and dogs, $70 \%$ of the orally administered radioactive-labeled chondroitin sulfate was found within 2 hours in the bloodstream and showed the highest concentrations in the intestine, liver, kidneys, synovial fluid, and cartilage after $24 \mathrm{~h}$ (Conte et al., 1995). In humans, about $20 \mu \mathrm{g} / \mathrm{ml}$ endogenously produced chondroitin sulfate is found in the blood circulation, and this level is constantly maintained without any effects of circadian rhythm (Jackson et al., 2009). Supplementing chondroitin sulfate with a single dose of $1,200 \mathrm{mg}$, as clinically used, did not reach a significant increase above endogenous chondroitin sulfate levels in the bloodstream within 2-4 h (Jackson et al., 2009), but a single dose of $4,000 \mathrm{mg}$ of chondroitin sulfate doubled the chondroitin sulfate levels in the blood plasma within 2-4 h (Volpi, 2002). By contrast, other studies have reported repeated application of exogenous chondroitin sulfate peaks during $2-8 \mathrm{~h}$ upon intravenous, intramuscular, or oral routes (Conte et al., 1991a; Ronca and Conte, 1993; Conte et al., 1995; Volpi, 2003). Furthermore, daily doses of $800-1,200 \mathrm{mg}$ of orally taken chondroitin sulfate significantly increased chondroitin plasma concentration within $24 \mathrm{~h}$ (Ronca and Conte, 1993; Conrozier, 1998). Of the orally taken chondroitin sulfate, about $30 \%$ of chondroitin sulfate (full-length and degraded) is excreted by the urine, whereas about $10 \%$ of the full-length and $20 \%$ of the degraded lower-molecular weight chondroitin sulfate is absorbed by the body (Conte et al., 1991b; Ronca and Conte, 1993; Ronca et al., 1998). Intact full-length chondroitin sulfate is taken up by cells via pinocytosis (McCarty et al., 2000). Orally taken chondroitin sulfate is absorbed in the proximal part of the small intestine (Souich, 2014). Probably most of the chondroitin sulfate is degraded in the colon and the cecum (Souich, 2014). After the partial excretion in the urine, chondroitin sulfate is mainly retained by the kidney and the liver (Pecly et al., 2006). However, accumulation of orally administered chondroitin sulfate in the joint tissue has been detected (Souich, 2014). Summing up, orally supplemented chondroitin sulfate is taken up by the body and reaches target tissues.

\section{Chondroitin Sulfate Impact on Age-Related Diseases}

Endogenous chondroitin sulfate in the extracellular space affects growth factor and matrix metalloprotease reservoir storage, as well as their presentation and release. Chondroitin sulfate binds directly to cell surface receptors, such as L- and P-selectins and CD44 (Figure 1), and thereby modulates malignant transformation, metastasis, and tumor cell migration (Afratis et al., 2012). The use of chondroitin sulfate and glucosamine is also associated with a lower risk for various cancers, especially colorectal cancer, lung cancer, and adenocarcinomas (Satia et al., 2009; Kantor et al., 2016; Rani et al., 2018). Supplementation of chondroitin sulfate and glucosamine beneficially altered the gut microbiome (Navarro et al., 2019), suggesting a possible mode-of-action via improving microbiome composition to lower colorectal cancer incidences.

One of the most studied age-related diseases with regards to chondroitin sulfate supplementation is osteoarthritis, although it is still controversial how effective chondroitin sulfate is in slowing the disease progression. Osteoarthritis is a major health complication affecting >237 million middle-aged people worldwide (GBD 2015 Disease and Injury Incidence and 
Prevalence Collaborators, 2016). Osteoarthritis is the wear down of weight-bearing joint cartilage, such as knees, hips, and vertebrae. During aging, the self-repair of the extracellular matrix of joints declines resulting in insufficient repair upon mechanical stress and damage leading to cartilage degeneration, stiffness, pain, and chronic inflammation (Jerosch, 2011).

The consensus of many randomized clinical trials concluded that chondroitin sulfate supplementation showed a moderate effect on pain relief, larger efficacy on slowing the agedependent shrinkage of the knee joint space, and improved knee function but also some considerable inconsistencies were observed across trials (Leeb et al., 2000; Jordan et al., 2003; Richy et al., 2003; Uebelhart et al., 2004; Michel et al., 2005; Clegg et al., 2006; Hathcock and Shao, 2007; Bruyère et al., 2008; Hochberg et al., 2008; Huskisson, 2008; Uebelhart, 2008; Kahan et al., 2009; Lee et al., 2009; Wildi et al., 2011; Zegels et al., 2013; Lomonte et al., 2018). A more detailed comparison is covered by these systematic reviews and meta-analyses (Wandel et al., 2010; Zhu et al., 2018; Honvo et al., 2019a; Fernández-Martín et al., 2021).

One contribution to the variable outcomes might be the manufacturing grade quality of chondroitin sulfate, which in some clinical trials, non-pharmaceutical grade chondroitin sulfate was included (Henrotin et al., 2014; Martel-Pelletier et al., 2015; Bruyère et al., 2017; Reginster and Veronese, 2021). Many tested food supplements had lower chondroitin sulfate concentration as indicated on their label and were less potent than pharmaceutical-grade chondroitin sulfate to inhibit inflammation markers in vitro (Stellavato et al., 2019). For instance, highly purified chondroitin sulfate administration reduced hand pain in a single-center, randomized, doubleblind, placebo-controlled clinical trial (Gabay et al., 2011). Thus, it is imperative to use pharmaceutical-grade chondroitin sulfate for treatment (Martel-Pelletier et al., 2015; Honvo et al., 2019b; Reginster and Veronese, 2021). Another variable might be the time of application during the disease progression. For instance, for osteoarthritis, the sooner chondroitin sulfate was applied after diagnosis (i.e., earlier stages of the disease), the higher was the chance of success and beneficial response (Bruyère et al., 2020). Taken together, pharmaceutical-grade chondroitin sulfate might alleviate and slow age-related disease progression.

\section{Chondroitin Sulfate Use is Associated With Human Longevity}

The question becomes whether chondroitin sulfate might be applicable as a preventative and geroprotective strategy in humans. There are three large cohort studies that showed a reduction in all-cause mortality of chondroitin sulfate users.

The first two studies examined the VITAL (Vitamins and Lifestyle) prospective cohort, which included both men and women aged 50-76. 77,718 people were examined for their use of vitamins, minerals, and other supplements in relation to mortality. These studies revealed that after 5 and 6.8 years of follow-up that the multivariate-adjusted hazard ratio of chondroitin sulfate users ( $>4$ days/week for $>3$ years) were 0.83 and 0.86 compared to non-users, suggesting a 17 and $14 \%$ significant decrease in risk of total mortality, respectively (Pocobelli et al., 2010; Bell et al., 2012).

The third study examined 16,686 people of the US NHANES cohort. This study found that after an 8.9-years follow-up, the multivariate-adjusted hazard ratio of a combinatory use of chondroitin sulfate with glucosamine was 0.73 for all-cause mortality and 0.42 for cardiovascular mortality compared to non-users, suggesting a $27 \%$ and a $58 \%$ lower likelihood of overall and cardiovascular mortality (King and Xiang, 2020). Thus, these longitudinal studies link chondroitin sulfate supplementation to human longevity.

\section{PERSPECTIVES}

Chondroitin sulfate supplementation is associated with reducing all-cause mortality in humans and increasing the lifespan of model organisms. But many gaps remain in our understanding of how chondroitin sulfate supplementation improves health during aging. Possible mechanisms include the reduction of chronic age-related inflammation and enhancement of extracellular matrix homeostasis. However, we need to define the missing steps in linking these two and possibly other mechanisms of chondroitin sulfate action to improve healthy aging. Such studies will provide new insights and help the development of therapeutic approaches that need to be tested in controlled clinical trials of chondroitin sulfate supplementation in age-matched individuals. Perhaps individualized assessment of chondroitin sulfate deficits might allow a personalized medical approach of chondroitin sulfate supplementation with other geroprotective drugs.

\section{AUTHOR CONTRIBUTIONS}

CE performed literature searches and wrote the manuscript.

\section{FUNDING}

Funding from the Swiss National Science Foundation PP00P3_190072 to CE.

\section{ACKNOWLEDGMENTS}

I thank Evelyne Bischof and the Ewald lab for critical comments on the manuscript. Figure 1 was created with Biorender (license number CT22PNT7QK). Chondroitin sulfate chemical structure backbone adapted from wikipedia.org. 


\section{REFERENCES}

Afratis, N., Gialeli, C., Nikitovic, D., Tsegenidis, T., Karousou, E., Theocharis, A. D., et al. (2012). Glycosaminoglycans: Key Players in Cancer Cell Biology and Treatment: GAG Targeting in Cancer Cell Biology. Febs J. 279, 1177-1197. doi:10.1111/j.1742-4658.2012.08529.x

Bakula, D., Aliper, A. M., Mamoshina, P., Petr, M. A., Teklu, A., Baur, J. A., et al. (2018). Aging and Drug Discovery. Aging 10, 3079-3088. doi:10.18632/ aging.101646

Balogh, L., Polyak, A., Mathe, D., Kiraly, R., Thuroczy, J., Terez, M., et al. (2008). Absorption, Uptake and Tissue Affinity of High-Molecular-Weight Hyaluronan after Oral Administration in Rats and Dogs. J. Agr Food Chem. 56, 10582-10593. doi:10.1021/jf8017029

Barardo, D., Thornton, D., Thoppil, H., Walsh, M., Sharifi, S., Ferreira, S., et al. (2017). The DrugAge Database of Aging-Related Drugs. Aging cell 16, 594-597. doi:10.1111/acel.12585

Bassleer, C. T., Combal, J. P., Bougaret, S., and Malaise, M. (1998). Effects of Chondroitin Sulfate and Interleukin-1 Beta on Human Articular Chondrocytes Cultivated in Clusters. Osteoarthr Cartil Oars Osteoarthr Res. Soc. 6, 196-204. doi:10.1053/joca.1998.0112

Bell, G. A., Kantor, E. D., Lampe, J. W., Shen, D. D., and White, E. (2012). Use of Glucosamine and Chondroitin in Relation to Mortality. Eur. J. Epidemiol. 27, 593-603. doi:10.1007/s10654-012-9714-6

Bonnans, C., Chou, J., and Werb, Z. (2014). Remodelling the Extracellular Matrix in Development and Disease. Nat. Rev. Mol. Cel Biol. 15, 786-801. doi:10.1038/ nrm3904

Bosset, S., Bonnet-Duquennoy, M., Barre, P., Chalon, A., Lazou, K., Kurfurst, R., et al. (2003). Decreased Expression of Keratinocyte Betal Integrins in Chronically Sun-Exposed Skin In Vivo. Br. J Dermatol 148, 770-778. doi:10.1046/j.1365-2133.2003.05159.x

Bruyère, O., Burlet, N., Delmas, P. D., Rizzoli, R., Cooper, C., and Reginster, J.-Y. (2008). Evaluation of Symptomatic Slow-Acting Drugs in Osteoarthritis Using the GRADE System. Bmc Musculoskelet. Di 9, 165. doi:10.1186/1471-2474-9-165

Bruyère, O., Cooper, C., Al-Daghri, N. M., Dennison, E. M., Rizzoli, R., and Reginster, J.-Y. (2017). Inappropriate Claims from Non-Equivalent Medications in Osteoarthritis: A Position Paper Endorsed by the European Society for Clinical and Economic Aspects of Osteoporosis, Osteoarthritis and Musculoskeletal Diseases (ESCEO). Aging Clin. Exp. Res. 30, 111-117. doi:10.1007/s40520-017-0861-1

Bruyère, O., Dardenne, N., Donneau, A.-F., and Reginster, J.-Y. (2020). Responder Profile to Pharmaceutical-Grade Chondroitin Sulfate: An Analysis of the CONCEPT Trial. Adv. Ther. 37, 4641-4648. doi:10.1007/s12325-020-01484-x

Calamia, V., Fernández-Puente, P., Mateos, J., Lourido, L., Rocha, B., Montell, E., et al. (2012a). Pharmacoproteomic Study of Three Different Chondroitin Sulfate Compounds on Intracellular and Extracellular Human Chondrocyte Proteomes. Mol. Cel Proteomics 11, M111.013417. doi:10.1074/ mcp.m111.013417

Calamia, V., Lourido, L., Fernández-Puente, P., Mateos, J., Rocha, B., Montell, E., et al. (2012b). Secretome Analysis of Chondroitin Sulfate-Treated Chondrocytes Reveals Anti-Angiogenic, Anti-Inflammatory and AntiCatabolic Properties. Arthritis Res. Ther. 14, R202. doi:10.1186/ar4040

Calamia, V., Ruiz-Romero, C., Rocha, B., Fernández-Puente, P., Mateos, J., Montell, E., et al. (2010). Pharmacoproteomic Study of the Effects of Chondroitin and Glucosamine Sulfate on Human Articular Chondrocytes. Arthritis Res. Ther. 12, R138. doi:10.1186/ar3077

Campo, G. M., Avenoso, A., Campo, S., D’Ascola, A., Traina, P., and Calatroni, A. (2008). Chondroitin-4-Sulphate Inhibits NF-kB Translocation and Caspase Activation in Collagen-Induced Arthritis in Mice. Osteoarthr Cartilage 16, 1474-1483. doi:10.1016/j.joca.2008.04.002

Campo, G. M., Avenoso, A., Campo, S., D’Ascola, A., Traina, P., Samà, D., et al. (2009). Glycosaminoglycans Modulate Inflammation and Apoptosis in LPS-Treated Chondrocytes. J. Cel Biochem 106, 83-92. doi:10.1002/ jcb. 21981

Chan, P.-S., Caron, J. P., and Orth, M. W. (2005). Effect of Glucosamine and Chondroitin Sulfate on Regulation of Gene Expression of Proteolytic Enzymes and Their Inhibitors in Interleukin-1-Challenged Bovine Articular Cartilage Explants. Am. J. Vet. Res. 66, 1870-1876. doi:10.2460/ajvr.2005.66.1870
Clegg, D. O., Reda, D. J., Harris, C. L., Klein, M. A., O’Dell, J. R., Hooper, M. M., et al. (2006). Glucosamine, Chondroitin Sulfate, and the Two in Combination for Painful Knee Osteoarthritis. New Engl. J. Med. 354, 795-808. doi:10.1056/ nejmoa052771

Conrozier, T. (1998). Anti-Arthrosis Treatments: Efficacy and Tolerance of Chondroitin Sulfates (CS 4\&6). Press. Méd. 27, 1862-1865.

Conte, A., Bernardi, M. D., Palmieri, L., Lualdi, P., Mautone, G., and Ronca, G. (1991a). Metabolic Fate of Exogenous Chondroitin Sulfate in Man. Arzneiforschung 41, 768-772.

Conte, A., Palmieri, L., Segnini, D., and Ronca, G. (1991b). Metabolic Fate of Partially Depolymerized Chondroitin Sulfate Administered to the Rat. Drug Exp. Clin. Res. 17, 27-33.

Conte, A., Volpi, N., Palmieri, L., Bahous, I., and Ronca, G. (1995). Biochemical and Pharmacokinetic Aspects of Oral Treatment with Chondroitin Sulfate. Arznei-forschung 45, 918-925.

Ewald, C. Y., Landis, J. N., Abate, J. P., Murphy, C. T., and Blackwell, T. K. (2015). Dauer-Independent insulin/IGF-1-Signalling Implicates Collagen Remodelling in Longevity. Nature 519, 97-101. doi:10.1038/nature14021

Ewald, C. Y. (2020). The Matrisome during Aging and Longevity: A Systems-Level Approach toward Defining Matreotypes Promoting Healthy Aging. Gerontology 66, 266-274. doi:10.1159/000504295

Farage, M. A., Miller, K. W., Elsner, P., and Maibach, H. I. (2008). Functional and Physiological Characteristics of the Aging Skin. Aging Clin. Exp. Res. 20, 195-200. doi:10.1007/bf03324769

Fernández-Martín, S., González-Cantalapiedra, A., Muñoz, F., GarcíaGonzález, M., Permuy, M., and López-Peña, M. (2021). Glucosamine and Chondroitin Sulfate: Is There Any Scientific Evidence for Their Effectiveness as Disease-Modifying Drugs in Knee Osteoarthritis Preclinical Studies?-A Systematic Review from 2000 to 2021. Animals 11, 1608. doi:10.3390/ani11061608

Gabay, C., Medinger-Sadowski, C., Gascon, D., Kolo, F., and Finckh, A. (2011). Symptomatic Effects of Chondroitin 4 and Chondroitin 6 Sulfate on Hand Osteoarthritis: A Randomized, Double-Blind, Placebo-Controlled Clinical Trial at a Single center. Arthritis Rheum. 63, 3383-3391. doi:10.1002/art.30574

Garantziotis, S., and Savani, R. C. (2019). Hyaluronan Biology: A Complex Balancing Act of Structure, Function, Location and Context. Matrix Biol. J Int Soc Matrix Biol. 78-79, 1-10. doi:10.1016/j.matbio.2019.02.002

GBD 2015 Disease and Injury Incidence and Prevalence Collaborators (2016). Global, Regional, and National Incidence, Prevalence, and Years Lived with Disability for 310 Diseases and Injuries, 1990-2015: A Systematic Analysis for the Global Burden of Disease Study 2015. Lancet Lond. Engl. 388, 1545-1602. doi:10.1016/s0140-6736(16)31678-6(

Giangreco, A., Goldie, S. J., Failla, V., Saintigny, G., and Watt, F. M. (2009). Human Skin Aging Is Associated with Reduced Expression of the Stem Cell Markers Betal Integrin and MCSP. J. Invest. Dermatol. 130, 604-608. doi:10.1038/jid.2009.297

Haefke, A., and Ewald, C. (2020). Tail Tendon Break Time for the Assessment of Aging and Longitudinal Healthspan in Mice. Bio-protocol 10, e3833. doi:10.21769/bioprotoc.3833

Hathcock, J. N., and Shao, A. (2007). Risk Assessment for Glucosamine and Chondroitin Sulfate. Regul. Toxicol. Pharm. 47, 78-83. doi:10.1016/ j.yrtph.2006.07.004

Henrotin, Y., Marty, M., and Mobasheri, A. (2014). What Is the Current Status of Chondroitin Sulfate and Glucosamine for the Treatment of Knee Osteoarthritis? Maturitas 78, 184-187. doi:10.1016/j.maturitas.2014.04.015

Hochberg, M. C., Zhan, M., and Langenberg, P. (2008). The Rate of Decline of Joint Space Width in Patients with Osteoarthritis of the Knee: a Systematic Review and Meta-Analysis of Randomized Placebo-Controlled Trials of Chondroitin Sulfate. Curr. Med. Res. Opin. 24, 3029-3035. doi:10.1185/03007990802434932

Honda, A., Abe, M., Miirota, S., and Mori, Y. (1979). The Effect of Aging on the Synthesis of Hexosamine-Containing Substances from Rat Costal Cartilage. J. Biochem. 85, 519-528. doi:10.1093/oxfordjournals.jbchem.a 132359

Honvo, G., Bruyère, O., Geerinck, A., Veronese, N., and Reginster, J.-Y. (2019a). Efficacy of Chondroitin Sulfate in Patients with Knee Osteoarthritis: A Comprehensive Meta-Analysis Exploring Inconsistencies in Randomized, Placebo-Controlled Trials. Adv. Ther. 36, 1085-1099. doi:10.1007/s12325019-00921-w

Honvo, G., Bruyère, O., and Reginster, J.-Y. (2019b). Update on the Role of Pharmaceutical-Grade Chondroitin Sulfate in the Symptomatic Management 
of Knee Osteoarthritis. Aging Clin. Exp. Res. 31, 1163-1167. doi:10.1007/ s40520-019-01253-z

Huskisson, E. (2008). Glucosamine and Chondroitin for Osteoarthritis. J. Int. Med. Res. 36, 1161-1179. doi:10.1177/147323000803600602

Huxley-Jones, J., Foord, S. M., and Barnes, M. R. (2008). Drug Discovery in the Extracellular Matrix. Drug Discov. Today 13, 685-694. doi:10.1016/ j.drudis.2008.05.005

Imada, K., Oka, H., Kawasaki, D., Miura, N., Sato, T., and Ito, A. (2010). AntiArthritic Action Mechanisms of Natural Chondroitin Sulfate in Human Articular Chondrocytes and Synovial Fibroblasts. Biol. Pharm Bull. 33, 410-414. doi:10.1248/bpb.33.410

Izumikawa, T., Sato, B., and Kitagawa, H. (2014). Chondroitin Sulfate Is Indispensable for Pluripotency and Differentiation of Mouse Embryonic Stem Cells. Sci. Rep-uk 4, 3701. doi:10.1038/srep03701

Jackson, C. G., Plaas, A. H., Sandy, J. D., Hua, C., Kim-Rolands, S., Barnhill, J. G., et al. (2009). The Human Pharmacokinetics of Oral Ingestion of Glucosamine and Chondroitin Sulfate Taken Separately or in Combination. Osteoarthr Cartil Oars Osteoarthr Res. Soc. 18, 297-302. doi:10.1016/j.joca.2009.10.013

Janssens, G. E., Lin, X.-X., Millan-Ariño, L., Kavšek, A., Sen, I., Seinstra, R. I., et al. (2019). Transcriptomics-Based Screening Identifies Pharmacological Inhibition of Hsp90 as a Means to Defer Aging. Cel Rep. 27, 467-480. doi:10.1016/ j.celrep.2019.03.044

Jerosch, J. (2011). Effects of Glucosamine and Chondroitin Sulfate on Cartilage Metabolism in OA: Outlook on Other Nutrient Partners Especially Omega-3 Fatty Acids. Int. J. Rheumatol. 2011, 1-17. doi:10.1155/2011/969012

Jomphe, C., Gabriac, M., Hale, T. M., Héroux, L., Trudeau, L.-É., Deblois, D., et al. (2007). Chondroitin Sulfate Inhibits the Nuclear Translocation of Nuclear Factor-Kb in Interleukin-1 $\beta$-Stimulated Chondrocytes. Basic Clin. Pharmaco 102, 59-65. doi:10.1111/j.1742-7843.2007.00158.x

Jordan, K. M., Arden, N. K., Doherty, M., Bannwarth, B., Bijlsma, J. W. J., Dieppe, P., et al. (2003). EULAR Recommendations 2003: an Evidence Based Approach to the Management of Knee Osteoarthritis: Report of a Task Force of the Standing Committee for International Clinical Studies Including Therapeutic Trials (ESCISIT). Ann. Rheum. Dis. 62, 1145-1155. doi:10.1136/ ard.2003.011742

Kahan, A., Uebelhart, D., Vathaire, F. D., Delmas, P. D., and Reginster, J.-Y. (2009). Long-term Effects of Chondroitins 4 and 6 Sulfate on Knee Osteoarthritis: The Study on Osteoarthritis Progression Prevention, a Two-Year, Randomized, Double-Blind, Placebo-Controlled Trial. Arthritis Rheum. 60, 524-533. doi:10.1002/art.24255

Kalman, D. S., Heimer, M., Valdeon, A., Schwartz, H., and Sheldon, E. (2008). Effect of a Natural Extract of Chicken Combs with a High Content of Hyaluronic Acid (Hyal-Joint) on Pain Relief and Quality of Life in Subjects with Knee Osteoarthritis: A Pilot Randomized Double-Blind PlaceboControlled Trial. Nutr. J. 7, 3. doi:10.1186/1475-2891-7-3

Kanaki, T., Makrantonaki, E., and Zouboulis, C. C. (2016). Biomarkers of Skin Aging. Rev. Endocr. Metab. Disord 17, 433-442. doi:10.1007/s11154-016-9392-x

Kantor, E. D., O'Connell, K., Du, M., Cao, C., Zhang, X., Lee, D. H., et al. (2020). Glucosamine and Chondroitin Use in Relation to C-Reactive Protein Concentration: Results by Supplement Form, Formulation, and Dose. J. Altern. Complement. Med. N Y 27, 150-159. doi:10.1089/acm.2020.0283

Kantor, E. D., Zhang, X., Wu, K., Signorello, L. B., Chan, A. T., Fuchs, C. S., et al. (2016). Use of Glucosamine and Chondroitin Supplements in Relation to Risk of Colorectal Cancer: Results from the Nurses' Health Study and Health Professionals Follow-Up Study: Use of Glucosamine and Chondroitin in Relation to Colorectal Cancer Risk. Int. J. Cancer 139, 1949-1957. doi:10.1002/ijc. 30250

Karsdal, M. A., Daniels, S. J., Nielsen, S. H., Bager, C., Rasmussen, D. G. K., Loomba, R., et al. (2020). Collagen Biology and Non-Invasive Biomarkers of Liver Fibrosis. Liver Int. 40, 736-750. doi:10.1111/liv.14390

Kim, E. J. E., and Lee, S-J. V. (2019). Recent Progresses on Anti-Aging Compounds and Their Targets in Caenorhabditis elegans. Translational Med. Aging 3, 121-124. doi:10.1016/j.tma.2019.11.003

King, D. E., and Xiang, J. (2020). Glucosamine/Chondroitin and Mortality in a US NHANES Cohort. J. Am. Board Fam. Med. 33, 842-847. doi:10.3122/ jabfm.2020.06.200110

Kloppenburg, M., Kroon, F. P., Blanco, F. J., Doherty, M., Dziedzic, K. S., Greibrokk, E., et al. (2018). 2018 Update of the EULAR Recommendations for the Management of Hand Osteoarthritis. Ann. Rheum. Dis. 78, 16-24. doi:10.1136/annrheumdis-2018-213826

Kusumoto, D., Seki, T., Sawada, H., Kunitomi, A., Katsuki, T., Kimura, M., et al. (2021). Anti-senescent Drug Screening by Deep Learning-Based Morphology Senescence Scoring. Nat. Commun. 12, 257. doi:10.1038/ s41467-020-20213-0

Kwok, J. C. F., Warren, P., and Fawcett, J. W. (2012). Chondroitin Sulfate: A Key Molecule in the Brain Matrix. Int. J. Biochem. Cel Biol. 44, 582-586. doi:10.1016/j.biocel.2012.01.004

Lee, Y. H., Woo, J.-H., Choi, S. J., Ji, J. D., and Song, G. G. (2009). Effect of Glucosamine or Chondroitin Sulfate on the Osteoarthritis Progression: A MetaAnalysis. Rheumatol. Int. 30, 357. doi:10.1007/s00296-009-0969-5

Leeb, B. F., Schweitzer, H., Montag, K., and Smolen, J. S. (2000). A Metaanalysis of Chondroitin Sulfate in the Treatment of Osteoarthritis. J. Rheumatol. 27, 205-211.

Legendre, F., Baugé, C., Roche, R., Saurel, A. S., and Pujol, J. P. (2008). Chondroitin Sulfate Modulation of Matrix and Inflammatory Gene Expression in IL-1 $\beta$ stimulated Chondrocytes - Study in Hypoxic Alginate Bead Cultures. Osteoarthr Cartilage 16, 105-114. doi:10.1016/j.joca.2007.05.020

Lila, A. M., Gromova, O. A., Torshin, I. Y., and Montell, E. (2018). Molecular Effects of Chondroitin Sulfate in Osteoarthritis and Herniated Discs. J. Rheumatol. Arthritic Dis 3, 1-11. doi:10.15226/2475-4676/3/3/00143

Liu, H., Guo, M., Xue, T., Guan, J., Luo, L., and Zhuang, Z. (2016). Screening Lifespan-Extending Drugs in Caenorhabditis elegans via Label Propagation on Drug-Protein Networks. BMC Syst. Biol. 10, 131. doi:10.1186/s12918-016$0362-4$

Lomonte, A. B. V., Mendonça, J. A., Brandão, G. de. C., and Castro, M. L. (2018). Multicenter, Randomized, Double-Blind Clinical Trial to Evaluate Efficacy and Safety of Combined Glucosamine Sulfate and Chondroitin Sulfate Capsules for Treating Knee Osteoarthritis. Adv. Rheumatol. 58, 41. doi:10.1186/s42358-0180041-9

López-Senra, E., Casal-Beiroa, P., López-Álvarez, M., Serra, J., González, P., Valcarcel, J., et al. (2020). Impact of Prevalence Ratios of Chondroitin Sulfate (CS)- 4 and -6 Isomers Derived from Marine Sources in Cell Proliferation and Chondrogenic Differentiation Processes. Mar. Drugs 18, 94. doi:10.3390/md18020094

Lucanic, M., Lithgow, G. J., and Alavez, S. (2013). Pharmacological Lifespan Extension of Invertebrates. Ageing Res. Rev. 12, 445-458. doi:10.1016/ j.arr.2012.06.006

Macke, E. L., Henningsen, E., Jessen, E., Zumwalde, N. A., Landowski, M., Western, D. E., et al. (2020). Loss of Chondroitin Sulfate Modification Causes Inflammation and Neurodegeneration in Skt Mice. Genetics 214, 121-134. doi:10.1534/genetics.119.302834

Martel-Pelletier, J., Farran, A., Montell, E., Vergés, J., and Pelletier, J.-P. (2015). Discrepancies in Composition and Biological Effects of Different Formulations of Chondroitin Sulfate. Mol. Basel Switz 20, 4277-4289. doi:10.3390/ molecules 20034277

McCarty, M. F., Russell, A. L., and Seed, M. P. (2000). Sulfated Glycosaminoglycans and Glucosamine May Synergize in Promoting Synovial Hyaluronic Acid Synthesis. Med. Hypotheses 54, 798-802. doi:10.1054/mehy.1999.0954

Michel, B. A., Stucki, G., Frey, D., Vathaire, F. D., Vignon, E., Bruehlmann, P., et al. (2005). Chondroitins 4 and 6 Sulfate in Osteoarthritis of the Knee: A Randomized, Controlled Trial. Arthritis Rheum. 52, 779-786. doi:10.1002/ art.20867

Mikami, T., and Kitagawa, H. (2013). Biosynthesis and Function of Chondroitin Sulfate. Biochim. Biophys. Acta Bba - Gen Subj 1830, 4719-4733. doi:10.1016/ j.bbagen.2013.06.006

Monfort, J., Nacher, M., Montell, E., Vila, J., Verges, J., and Benito, P. (2005). Chondroitin Sulfate and Hyaluronic Acid (500-730 Kda) Inhibit Stromelysin-1 Synthesis in Human Osteoarthritic Chondrocytes. Drug Exp. Clin. Res. 31, 71-76.

Moskalev, A., and Shaposhnikov, M. (2011). Pharmacological Inhibition of NF-Kb Prolongs Lifespan of Drosophila melanogaster. Aging 3, 391-394. doi:10.18632/ aging. 100314

Navarro, S. L., Levy, L., Curtis, K. R., Lampe, J. W., and Hullar, M. A. J. (2019). Modulation of Gut Microbiota by Glucosamine and Chondroitin in a Randomized, Double-Blind Pilot Trial in Humans. Microorg 7, 610. doi:10.3390/microorganisms7120610 
Navarro, S. L., White, E., Kantor, E. D., Zhang, Y., Rho, J., Song, X., et al. (2015). Randomized Trial of Glucosamine and Chondroitin Supplementation on Inflammation and Oxidative Stress Biomarkers and Plasma Proteomics Profiles in Healthy Humans. Plos One 10, e0117534. doi:10.1371/journal.pone.0117534

Omata, T., Itokazu, Y., Inoue, N., and Segawa, Y. (2000). Effects of Chondroitin Sulfate-C on Articular Cartilage Destruction in Murine Collagen-Induced Arthritis. Arzneimittelforschung 50, 148-153. doi:10.1055/s-0031-1300180

Pecly, I. M. D., Melo-Filho, N. M., and Mourão, P. A. S. (2006). Effects of Molecular Size and Chemical Structure on Renal and Hepatic Removal of Exogenously Administered Chondroitin Sulfate in Rats. Biochim. Biophys. Acta Bba - Gen Subj 1760, 865-876. doi:10.1016/j.bbagen.2005.11.009

Petrascheck, M., Ye, X., and Buck, L. B. (2007). An Antidepressant that Extends Lifespan in Adult Caenorhabditis elegans. Nature 450, 553-556. doi:10.1038/ nature05991

Pocobelli, G., Kristal, A. R., Patterson, R. E., Potter, J. D., Lampe, J. W., Kolar, A., et al. (2010). Total Mortality Risk in Relation to Use of Less-Common Dietary Supplements. Am. J. Clin. Nutr. 91, 1791-1800. doi:10.3945/ ajcn.2009.28639

Rani, A., Baruah, R., and Goyal, A. (2018). Prebiotic Chondroitin Sulfate Disaccharide Isolated from Chicken Keel Bone Exhibiting Anticancer Potential against Human Colon Cancer Cells. Nutr. Cancer 71, 1-15. doi:10.1080/01635581.2018.1521446

Reginster, J.-Y., and Veronese, N. (2021). Highly Purified Chondroitin Sulfate: a Literature Review on Clinical Efficacy and Pharmacoeconomic Aspects in Osteoarthritis Treatment. Aging Clin. Exp. Res. 33, 37-47. doi:10.1007/ s40520-020-01643-8

Richy, F., Bruyere, O., Ethgen, O., Cucherat, M., Henrotin, Y., and Reginster, J.-Y. (2003). Structural and Symptomatic Efficacy of Glucosamine and Chondroitin in Knee Osteoarthritis: A Comprehensive Meta-Analysis. Arch. Intern. Med. 163, 1514-1522. doi:10.1001/archinte.163.13.1514

Ronca, F., Palmieri, L., Panicucci, P., and Ronca, G. (1998). Anti-inflammatory Activity of Chondroitin Sulfate. Osteoarthr Cartilage 6, 14-21. doi:10.1016/ s1063-4584(98)80006-x

Ronca, G., and Conte, A. (1993). Metabolic Fate of Partially Depolymerized Shark Chondroitin Sulfate in Man. Int. J. Clin. Pharm. Res. 13 (Suppl. 1), $27-34$.

Satia, J. A., Littman, A., Slatore, C., Galanko, J., and White, E. (2009). Associations of Specialty Herbal Supplements with Lung and Colorectal Cancer Risk. Faseb J. 23, 222.3. doi:10.1096/fasebj.23.1_supplement.222.3

Schinzel, R. T., Higuchi-Sanabria, R., Shalem, O., Moehle, E. A., Webster, B. M., Joe, L., et al. (2019). The Hyaluronidase, TMEM2, Promotes ER Homeostasis and Longevity Independent of the UPRER. Cell 179, 1306-1318. doi:10.1016/ j.cell.2019.10.018

Shuster, S., Black, M. M., and McVitie, E. (1975). The Influence of Age and Sex on Skin Thickness, Skin Collagen and Density. Br. J. Dermatol. 93, 639-643. doi:10.1111/j.1365-2133.1975.tb05113.x

Souich, P. D. (2014). Absorption, Distribution and Mechanism of Action of SYSADOAS. Pharmacol. Therapeut 142, 362-374. doi:10.1016/ j.pharmthera.2014.01.002

Souich, P. D., García, A. G., Vergés, J., and Montell, E. (2009). Immunomodulatory and Anti-inflammatory Effects of Chondroitin Sulphate. J. Cel Mol Med 13, 1451-1463. doi:10.1111/j.1582-4934.2009.00826.x

Statzer, C., and Ewald, C. Y. (2020). The Extracellular Matrix Phenome Across Species. Matrix Biol. Plus 8, 100039. doi:10.1016/j.mbplus.2020.100039

Statzer, C., Jongsma, E., Liu, S. X., Dakhovnik, A., Wandrey, F., Mozharovskyi, P., et al. (2021). Youthful and Age-related Matreotypes Predict Drugs Promoting Longevity. Aging Cell, e13441, 2021 . [Epub ahead of print]. doi:10.1111/acel.13441

Stellavato, A., Restaino, O. F., Vassallo, V., Finamore, R., Ruosi, C., Cassese, E., et al. (2019). Comparative Analyses of Pharmaceuticals or Food Supplements Containing Chondroitin Sulfate: Are Their Bioactivities Equivalent? Adv. Ther. 36, 3221-3237. doi:10.1007/s12325-019-01064-8

Sugawara, K., Tsuruta, D., Ishii, M., Jones, J. C. R., and Kobayashi, H. (2008). Laminin-332 and -511 in Skin. Exp. Dermatol. 17, 473-480. doi:10.1111/j.16000625.2008.00721.x
Sukhikh, S., Babich, O., Prosekov, A., Patyukov, N., and Ivanova, S. (2020). Future of Chondroprotectors in the Treatment of Degenerative Processes of Connective Tissue. Pharm 13, 220. doi:10.3390/ph13090220

Tahiri, K., Korwin-Zmijowska, C., Richette, P., Heraud, F., Chevalier, X., Savouret, J.-F., et al. (2007). Natural Chondroitin Sulphates Increase Aggregation of Proteoglycan Complexes and Decrease Adamts-5 Expression in Interleukin 1 -treated Chondrocytes. Ann. Rheum. Dis. 67, 696-702. doi:10.1136/ard.2007.078600

Taniguchi, S., Ryu, J., Seki, M., Sumino, T., Tokuhashi, Y., and Esumi, M. (2011). Long-Term Oral Administration of Glucosamine or Chondroitin Sulfate Reduces Destruction of Cartilage and Up-Regulation of MMP-3 mRNA in a Model of Spontaneous Osteoarthritis in Hartley guinea Pigs: Oral Glucosamine or Chondroitin Sulfate in an Oa Model. J. Orthopaed Res. 30, 673-678. doi:10.1002/jor.22003

Teuscher, A. C., Statzer, C., Pantasis, S., Bordoli, M. R., and Ewald, C. Y. (2019). Assessing Collagen Deposition During Aging in Mammalian Tissue and in Caenorhabditis elegans. Methods Mol. Biol. Clifton N J 1944, 169-188. doi:10.1007/978-1-4939-9095-5_13

Tilstra, J. S., Clauson, C. L., Niedernhofer, L. J., and Robbins, P. D. (2011). NF-kB in Aging and Disease. Aging Dis. 2, 449-465.

Uebelhart, D. (2008). Clinical Review of Chondroitin Sulfate in Osteoarthritis. Osteoarthr Cartilage 16, S19-S21. doi:10.1016/ j.joca.2008.06.006

Uebelhart, D., Malaise, M., Marcolongo, R., DeVathaire, F., Piperno, M., Mailleux, E., et al. (2004). Intermittent Treatment of Knee Osteoarthritis with Oral Chondroitin Sulfate: A One-Year, Randomized, Double-Blind, Multicenter Study versus Placebo. Osteoarthr Cartilage 12, 269-276. doi:10.1016/ j.joca.2004.01.004

Vallières, M., and Souich, P. D. (2010). Modulation of Inflammation by Chondroitin Sulfate. Osteoarthr Cartilage 18, S1-S6. doi:10.1016/ j.joca.2010.02.017

Varani, J., Dame, M. K., Rittie, L., Fligiel, S. E. G., Kang, S., Fisher, G. J., et al. (2006). Decreased Collagen Production in Chronologically Aged Skin Roles of Age-Dependent Alteration in Fibroblast Function and Defective Mechanical Stimulation. Am. J. Pathol. 168, 1861-1868. doi:10.2353/ajpath.2006.051302

Volpi, N. (2003). Oral Absorption and Bioavailability of Ichthyic Origin Chondroitin Sulfate in Healthy Male Volunteers. Osteoarthr Cartilage 11, 433-441. doi:10.1016/s1063-4584(03)00051-7

Volpi, N. (2002). Oral Bioavailability of Chondroitin Sulfate (Condrosulf) and its Constituents in Healthy Male Volunteers. Osteoarthr Cartil Oars Osteoarthr Res. Soc. 10, 768-777. doi:10.1053/joca.2002.0824

Wandel, S., Jüni, P., Tendal, B., Nüesch, E., Villiger, P. M., Welton, N. J., et al. (2010). Effects of Glucosamine, Chondroitin, or Placebo in Patients with Osteoarthritis of Hip or Knee: Network Meta-Analysis. Bmj Clin. Res. Ed. 341, c4675. doi:10.1136/bmj.c4675

Weimer, S., Priebs, J., Kuhlow, D., Groth, M., Priebe, S., Mansfeld, J., et al. (2014). D-Glucosamine Supplementation Extends Life Span of Nematodes and of Ageing Mice. Nat. Commun. 5, 3563. doi:10.1038/ ncomms 4563

Wick, G., Grundtman, C., Mayerl, C., Wimpissinger, T.-F., Feichtinger, J., Zelger, B., et al. (2013). The Immunology of Fibrosis. Annu. Rev. Immunol. 31, 107-135. doi:10.1146/annurev-immunol-032712-095937

Wildi, L. M., Raynauld, J.-P., Martel-Pelletier, J., Beaulieu, A., Bessette, L., Morin, F., et al. (2011). Chondroitin Sulphate Reduces Both Cartilage Volume Loss and Bone Marrow Lesions in Knee Osteoarthritis Patients Starting as Early as 6 Months after Initiation of Therapy: A Randomised, Double-Blind, PlaceboControlled Pilot Study Using MRI. Ann. Rheum. Dis. 70, 982-989. doi:10.1136/ ard.2010.140848

Xu, C.-X., Jin, H., Chung, Y.-S., Shin, J.-Y., Lee, K.-H., Beck, G. R., et al. (2008). Chondroitin Sulfate Extracted from Ascidian Tunic Inhibits Phorbol EsterInduced Expression of Inflammatory Factors VCAM-1 and COX-2 by Blocking NF-Kb Activation in Mouse Skin. J. Agr Food Chem. 56, 9667-9675. doi:10.1021/jf801578x

Yang, S., Gigout, S., Molinaro, A., Naito-Matsui, Y., Hilton, S., Foscarin, S., et al. (2021). Chondroitin 6-sulphate Is Required for Neuroplasticity and Memory in Ageing. Mol. Psychiatr. [Epub ahead of print]. doi:10.1038/s41380-021-01208-9 
Ye, X., Linton, J. M., Schork, N. J., Buck, L. B., and Petrascheck, M. (2014). A Pharmacological Network for Lifespan Extension in Caenorhabditis elegans. Aging cell 13, 206-215. doi:10.1111/acel.12163

Zegels, B., Crozes, P., Uebelhart, D., Bruyère, O., and Reginster, J. Y. (2013). Equivalence of a Single Dose $(1200 \mathrm{Mg}$ ) Compared to a Three-Time a Day Dose $(400 \mathrm{Mg})$ of Chondroitin $4 \& 6$ Sulfate in Patients with Knee Osteoarthritis. Results of a Randomized Double Blind Placebo Controlled Study. Osteoarthr Cartilage 21, 22-27. doi:10.1016/ j.joca.2012.09.017

Zhang, G., Li, J., Purkayastha, S., Tang, Y., Zhang, H., Yin, Y., et al. (2013). Hypothalamic Programming of Systemic Ageing Involving IKK- $\beta$, NF-Kb and GnRH. Nature 497, 211-216. doi:10.1038/nature12143

Zhu, X., Sang, L., Wu, D., Rong, J., and Jiang, L. (2018). Effectiveness and Safety of Glucosamine and Chondroitin for the Treatment of Osteoarthritis: A MetaAnalysis of Randomized Controlled Trials. J. Orthop. Surg. Res. 13, 170. doi:10.1186/s13018-018-0871-5
Conflict of Interest: The author declares that the research was conducted in the absence of any commercial or financial relationships that could be construed as a potential conflict of interest.

Publisher's Note: All claims expressed in this article are solely those of the authors and do not necessarily represent those of their affiliated organizations, or those of the publisher, the editors and the reviewers. Any product that may be evaluated in this article, or claim that may be made by its manufacturer, is not guaranteed or endorsed by the publisher.

Copyright $\odot 2021$ Ewald. This is an open-access article distributed under the terms of the Creative Commons Attribution License (CC BY). The use, distribution or reproduction in other forums is permitted, provided the original author(s) and the copyright owner(s) are credited and that the original publication in this journal is cited, in accordance with accepted academic practice. No use, distribution or reproduction is permitted which does not comply with these terms. 